\title{
Diet quality and its relationship with central obesity among Mexican Americans: findings from National Health and Nutrition Examination Survey (NHANES) 1999-2012
}

\author{
Yilin Yoshida ${ }^{1}$, Richard Scribner ${ }^{2}$, Liwei Chen ${ }^{3}$, Stephanie Broyles ${ }^{4,5}$, Stephen Phillippi ${ }^{4}$ \\ and Tung-Sung Tseng ${ }^{4, *}$ \\ 'Department of Health Management and Informatics, School of Medicine, University of Missouri, Columbia, MO, \\ USA: ${ }^{2}$ Department of Epidemiology, School of Public Health, Louisiana State University Health Sciences Center at \\ New Orleans, New Orleans, LA, USA: ${ }^{3}$ Department of Public Health Sciences, Clemson University, Clemson, SC, \\ USA: ${ }^{4}$ Department of Behavioral and Community Health Sciences, School of Public Health, Louisiana State University \\ Health Sciences Center at New Orleans, 2020 Gravier Street, 3rd Floor, New Orleans, LA 701 12, USA: \\ ${ }^{5}$ Pennington Biomedical Research Center, Louisiana State University, Baton Rouge, LA, USA
}

Submitted 22 July 2016: Final revision received 24 0ctober 2016: Accepted 27 0ctober 2016: First published online 15 December 2016

\begin{abstract}
Objective: Using the Healthy Eating Index-2010 (HEI-2010), the present study aimed to examine diet quality and the impact of overall diet quality and its components on central obesity among Mexican-American men and women.

Design: Cross-sectional data from NHANES 1999-2012 were used. The HEI-2010

data, including twelve components for a total score of 100, were collected with a $24 \mathrm{~h}$ recall interview. Central obesity was defined as a waist circumference of $\geq 88 \mathrm{~cm}$ for women and $\geq 102 \mathrm{~cm}$ for men. Weighted logistic regressions were performed to assess associations between HEI-2010 scores and central obesity. Setting: National Health and Nutrition Examination Survey (NHANES) 1999-2012. Subjects: A total of 6847 Mexican Americans aged $\geq 20$ years with reliable dietary recall status and non-pregnancy status.

Results: Higher HEI-2010 total score was associated with lower odds of central obesity in Mexican-American men (OR; 95\% CI=0.98; 0.98, 1.00). Among all Mexican Americans, one-unit higher score of total fruit and sodium (i.e. lower level of intake) was associated with $4 \%(0.96 ; 0.93,0.99)$ and $2 \%(0.98 ; 0.96,0.99)$ lower odds of central obesity, respectively. However, a higher total proteins score was associated with higher odds of central obesity $(1.08 ; 1.00,1 \cdot 16)$. In genderspecific analyses, a higher whole fruit or sodium score was inversely associated with central obesity in men but not in women.

Conclusions: HEI-2010 scores of total fruit and sodium were inversely associated with central obesity among all Mexican Americans. However, total proteins score and central obesity was positively associated. In Mexican-American men, HEI-2010 total and whole fruit scores were inversely associated with central obesity.
\end{abstract}

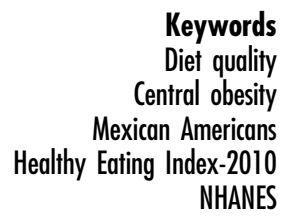

NHANES
Nutrition-related conditions such as central obesity have disproportionately affected Mexican Americans ${ }^{(1,2)}$. Central obesity is known as excessive waist size resulting from accumulation of abnormal $\mathrm{fat}^{(2,3)}$. Compared with overall obesity, central obesity is associated with higher risks for metabolic diseases; of these diseases, diabetes, hypertension, dyslipidaemia and insulin resistance are most prevalent in Mexican Americans ${ }^{(4-7)}$.

Diet is an important lifestyle factor that has been related to body weight and composition and is critical in preventing overweight and obesity. Emerging studies are examining weight outcomes in relation to diet quality, in addition to individual food groups, specific nutrient(s) or energy intake ${ }^{(8,9)}$. Diet quality is used to evaluate the overall dietary pattern and to identify nutrition adequacy and balance ${ }^{(10)}$. One of multiple methods to measure diet quality, the Healthy Eating Index (HEI), was developed by the US Department of Agriculture based on the Dietary Guidelines for Americans ${ }^{(11)}$ and has been adopted in many studies $^{(3,12,13)}$. The total HEI score provides an overall measure of diet quality, while the component scores used to calculate the total HEI score offer opportunities to study 
important components of dietary intake and their health impact $^{(3)}$. Previous studies have suggested inverse relationships between diet quality and risks for overall obesity, CVD and diabetes in general adult populations ${ }^{(14-16)}$. However, there is a relative shortage of knowledge on whether overall diet quality impacts central obesity among Mexican Americans.

Additionally, little is known about which components of diet quality affect body weight and composition among Mexican-American adults. Using the HEI-2005, Tande and colleagues found that a higher fruit score (all forms of fruit) was associated with $2.6 \%$ lower odds of central obesity in women in the USA ${ }^{(3)}$. Among men, a higher score of saturated fat was associated with $3 \%$ lower odds of central obesity ${ }^{(3)}$. The HEI-2010 made several changes according to the updated Dietary Guidelines for Americans 2010. These changes included adding a category of seafood and plant proteins to capture specific choices from the protein group, keeping whole grains and refined grains separate to assess the overconsumption of unhealthy grains, and using a ratio of PUFA + MUFA to SFA to replace oils and saturated fat to acknowledge the recommendation to replace saturated fat with mono- and polyunsaturated fat ${ }^{(11)}$. Additional research is needed to better understand the new HEI-2010 components and their relationships with central obesity. Using the HEI-2010, Drenowatz and colleagues showed that a higher sodium score, reflecting a lower intake, was associated with lower odds of overweight and obesity ${ }^{(16)}$. In contrast, a higher score of total proteins, indicating a higher intake, was associated with significantly higher odds of obesity and this association was significant in men but not in women $^{(16)}$. Drenowatz et al.'s research was done utilizing a sample of young, college-educated people of mostly European descent ${ }^{(16)}$. There is still a lack of evidence of the effects of HEI-2010 components on central obesity among Mexican Americans, where a great proportion of individuals are of relatively low socio-economic status ${ }^{(17)}$.

Previous studies indicated potential gender differences regarding diet quality and weight ${ }^{(18-20)}$. Although women are more likely to report eating 'healthier foods ${ }^{(16,21)}$, they seem to consume more sugar-laden foods than men, such as cookies, chocolate and ice cream ${ }^{(22,23)}$. Men consume a greater percentage of their energy intake from protein $^{(22,24,25)}$. In addition, they tend to consume more alcohol than women ${ }^{(24,26)}$. Furthermore, there may be variations in self-report biases by gender, which could affect the association between diet quality and obesity outcomes $^{(16,23)}$. Women may have a greater reporting bias, possibly due to their greater emphasis on a healthy diet than men ${ }^{(16,23)}$. Among Mexican Americans, while national data showed that the prevalence of obesity outcomes was higher in women than in men ${ }^{(27)}$, regional data, in California and the Mexico-Texas border region for example, showed that Mexican-American men had the same likelihood to be overweight and obese as their female counterparts ${ }^{(28,29)}$. Mixed findings regarding the diet and obesity disparities between Mexican-American men and women indicate a need for further investigation.

Taking advantage of a comprehensive diet quality assessment tool, the HEI-2010, in a national sample of Mexican Americans, the present study aimed to evaluate diet quality and examine the relationship between diet quality and central obesity among Mexican-American men and women.

\section{Methods}

\section{Study design and data source}

The current study utilized a cross-sectional design based on data from the continuous National Health and Nutrition Examination Survey (NHANES), cycle 1999-2000 to cycle 2010-2012. The continuous NHANES is a complex, multistage probability sample of US non-institutionalized civilians that started in 1999. Each two-year survey cycle examines a nationally representative sample of approximately 10000 persons and collects information on the health and nutritional status of adults and children. Some subgroups, including Mexican Americans, are oversampled, so that the reliability and precision of the estimated health status indicators for these groups are ensured (detailed information on NHANES is described elsewhere) ${ }^{(30)}$. About 72000 ( $n$ 71916) individuals completed an in-person home interview in the seven study cycles. Just under 69000 ( $n$ 68705) completed an interview and an examination in a mobile examination centre, among which 7096 were Mexican-American adults aged 20 years or older. After removing 249 Mexican-American adults with missing dietary data or waist circumference measurement, a total of 6847 individuals with reliable dietary recall status and non-pregnancy status were included in the present study (see online supplementary material, Supplemental Fig. 1). Data from the US Department of Agriculture's Food Pattern Equivalents Database (FPED) were obtained to translate NHANES dietary data into equivalent servings of the major food groups and subgroups according to the HEI-2010 ${ }^{(31)}$. The National Center for Health Statistics' Research Ethics Review Board approved NHANES and informed consent was obtained from all participants ${ }^{(30)}$.

\section{Measures}

The primary study outcome, central obesity, was categorized based on physical exam information from NHANES. Central obesity was defined as a waist circumference of $\geq 88 \mathrm{~cm}$ for women and $\geq 102 \mathrm{~cm}$ for $\operatorname{men}^{(32,33)}$. Dietary intake data were obtained from the NHANES in-person $24 \mathrm{~h}$ recall interview ${ }^{(30)}$. This information included names of foods, times they were consumed, type of meal or snack, and where the food was consumed. Instructions were provided to the participants orally in English and/or 
Spanish. Measurement aids and visuals were used to quantify the foods and beverages that were reported. The dietary assessment was carried out by a trained interviewer in a mobile examination centre ${ }^{(30)}$. FPED was used to examine consumption in terms of food group equivalent servings. FPED translated dietary recall data into equivalent servings of the major food groups and subgroups. Mixed foods were disaggregated (i.e. broken down into their ingredients), with solid fats and added sugars counted separately ${ }^{(11)}$. Diet quality was calculated by using the HEI-2010. Briefly, the HEI-2010 was designed to evaluate compliance with the key diet-related recommendations of the 2010 Dietary Guidelines for Americans. The HEI-2010 was summed to a maximum total score of 100. HEI-2010 scores were density-based; that is, the amount of a dietary component of interest consumed (i.e. a food group or nutrient) was divided by total energy and multiplied by 1000 or expressed as a percentage of energy ${ }^{(11)}$. The density approach measures diet quality, which is a mix of food, rather than diet quantity ${ }^{(11)}$.

Sociodemographic covariates included gender, age (20-40, 41-60 or >60 years), education (less than high school, high school or equivalent, or more than high school), marital status (yes or no) and poverty-to-income ratio (PIR $<1,1 \leq \mathrm{PIR}<3$ or $\mathrm{PIR} \geq 3$ ), smoking status (never, former or current) and alcohol drinking status (never, former or current). Insurance coverage was categorized into: (i) public insurance including Medicare, Medicaid and other forms of government insurance; (ii) private insurance; and (iii) no health insurance. Acculturation was constructed as an acculturation score, which was based on three proxy measures: (i) country of birth; (ii) language spoken at home; and (iii) length of time in the USA. Combining country of birth and length of time in the USA, a score of $0-3$ was assigned based on four categories ( $3=$ US-born; $2=$ foreign-born and lived in the USA for $\geq 20$ years; $1=$ foreign-born and lived in the USA for 10-19 years; $0=$ foreign-born and lived in the USA for $<10$ years). A score of $0-2$ was assigned to the language spoken at home $(2=$ English only or pro-English; $1=$ both English and Spanish equally; $0=$ Spanish or pro-Spanish). These scores were summed to yield a total acculturation score, ranging from 0 (least acculturated) to 5 (most acculturated). This scale was based on one used in a previous study of Hispanic and Chinese populations ${ }^{(34)}$. The variable of physical activity was examined by using the physical activity questionnaire items employed in NHANES. Participants were asked their engagement in moderate-to-vigorous physical activity during the past $30 \mathrm{~d}$ related to transportation, household/domestic tasks and leisure-time activities. Their responses were translated into minutes of moderate-to-vigorous physical activity per week. Each participant's combined weekly duration of moderate-to-vigorous physical activity was grouped into one of two categories ( $<150$ or $\geq 150 \mathrm{~min} /$ week) based upon their achievement of current activity guidelines ${ }^{(35)}$. Lastly, data release number (SDDSRVRY) was taken into account in the analysis to adjust for potential different distributions of sampled populations in different survey cycles.

\section{Analyses}

All statistical analyses for the study were conducted using the statistical software package SAS version 9.4. Multivariable logistic regressions were conducted to investigate the association between HEI-2010 total score and central obesity, as well as the associations between HEI-2010 component scores and central obesity. Considering the complexity of the sampling design, survey-related commands (e.g. PROC SURVEYMEANS) were employed to adjust for the complex survey design effect. In particular, the primary sampling unit and stratum for each observation were taken into account in the analysis $^{(30)}$.

\section{Results}

Table 1 presents sociodemographic and behavioural characteristics, as well as central obesity status of Mexican Americans. The mean acculturation score was 2.4 for Mexican Americans in NHANES cycles 1999-2000 to 2010-2012. Almost 51\% of participants were centrally obese. In gender-specific analyses, women appeared less likely to be current smokers (12 v. 27\%) and current drinkers (53 v. 79\%), but more likely to achieve the Physical Activity Guidelines for Americans (63 v. 52\%). However, in comparison to men, women were more likely to be centrally obese ( $68 v$. 36\%).

HEI-2010 scores by gender are presented in Table 2. The mean HEI-2010 total score for all Mexican Americans in NHANES cycles 1999-2000 to 2010-2012 was 50. Mexican-American women appeared have better overall diet quality (HEI-2010 total score: $51 \cdot 1 v .48 \cdot 4, P<0 \cdot 001$ ) than their male counterparts. Compared with men, women also had higher scores across most HEI-2010 component categories, except in the categories of greens and beans $(2 \cdot 0$ v. $2 \cdot 1, P<0 \cdot 001)$, total proteins $(4.3 v .4 .5, P<0.001)$ and fatty acids $(5 \cdot 1 v .5 \cdot 2, P<0 \cdot 001)$, where women scored lower than their male counterparts. Mexican-American women had higher mean HEI-2010 total scores than Mexican-American men (Fig. 1).

Table 3 presents findings from multivariable logistic regression models assessing the relationship between HEI-2010 scores and central obesity. A higher HEI-2010 total score was significantly associated with lower odds of central obesity (OR $=0.98$; $95 \%$ CI 0.98, 1.00) in MexicanAmerican men, but not in women (OR = 1.00; $95 \%$ CI 0.99, 1.01). Among all Mexican Americans, a one-unit higher score of total fruit and sodium was associated with $4 \%$ $(\mathrm{OR}=0.96 ; 95 \% \mathrm{CI} 0.93,0.99)$ and $2 \%(\mathrm{OR}=0.98 ; 95 \% \mathrm{CI}$ $0.96,0.99)$ lower odds of central obesity, respectively (note that a higher sodium score indicates a lower level of 
Table 1 Characteristics of Mexican-American men and women aged $\geq 20$ years ( $n 6847$ ), National Health and Nutrition Examination Survey (NHANES) 1999-2012

\begin{tabular}{|c|c|c|c|c|c|c|}
\hline & \multicolumn{2}{|c|}{ All } & \multicolumn{2}{|c|}{ Men } & \multicolumn{2}{|c|}{ Women } \\
\hline & $n$ & $\%$ & $n$ & $\%$ & $n$ & $\%$ \\
\hline \multicolumn{7}{|l|}{ Age (years) } \\
\hline $20-40$ & 3096 & 61.5 & 1382 & $63 \cdot 6$ & 1590 & $59 \cdot 2$ \\
\hline $41-60$ & 1948 & 29.0 & 941 & 28.5 & 940 & 29.6 \\
\hline$>60$ & 1803 & 9.5 & 788 & 8.0 & 899 & 11.2 \\
\hline \multicolumn{7}{|l|}{ Education } \\
\hline Less than high school & 4047 & 53.0 & 1896 & $55 \cdot 1$ & 1954 & $50 \cdot 6$ \\
\hline High school or equivalent & 1235 & $20 \cdot 7$ & 563 & 21.4 & 622 & $20 \cdot 0$ \\
\hline More than high school & 1550 & $26 \cdot 3$ & 649 & $23 \cdot 4$ & 844 & 29.4 \\
\hline \multicolumn{7}{|l|}{ Income } \\
\hline $\mathrm{PIR}<1.0 \dagger$ & 1929 & $31 \cdot 3$ & 830 & $29 \cdot 1$ & 1026 & 33.7 \\
\hline $1 \leq \mathrm{PIR}<3$ & 2039 & 47.8 & 1413 & 49.9 & 1422 & $45 \cdot 5$ \\
\hline$P I R \geq 3$ & 1550 & $20 \cdot 9$ & 567 & 21.9 & 587 & $20 \cdot 8$ \\
\hline \multicolumn{7}{|l|}{ Marital status } \\
\hline Married & 3971 & $56 \cdot 6$ & 1953 & 58.5 & 1849 & 54.5 \\
\hline \multicolumn{7}{|l|}{ Health insurance } \\
\hline No & 2944 & $51 \cdot 1$ & 1451 & 54.9 & 1387 & $46 \cdot 9$ \\
\hline Public & 1544 & $14 \cdot 0$ & 573 & 9.9 & 888 & $18 \cdot 6$ \\
\hline Private & 2257 & 34.9 & 1052 & $35 \cdot 2$ & 1106 & 34.5 \\
\hline \multicolumn{7}{|l|}{ Smoking } \\
\hline Non-smoker & 4120 & 61.5 & 1391 & 49.4 & 2539 & 74.9 \\
\hline Former & 1494 & $18 \cdot 6$ & 923 & $23 \cdot 5$ & 506 & $13 \cdot 2$ \\
\hline Current & 1224 & 19.9 & 795 & $27 \cdot 1$ & 378 & 12.0 \\
\hline \multicolumn{7}{|l|}{ Alcohol drinking } \\
\hline Non-drinker & 997 & $15 \cdot 4$ & 111 & 4.4 & 886 & $27 \cdot 6$ \\
\hline Former & 1164 & $17 \cdot 7$ & 555 & $16 \cdot 5$ & 609 & $19 \cdot 2$ \\
\hline Current & 3437 & 66.9 & 2001 & $79 \cdot 2$ & 1436 & 53.2 \\
\hline \multicolumn{7}{|l|}{ Physical activity } \\
\hline Met PAGA $(\geq 150 \mathrm{~min} /$ week $) \ddagger$ & 4084 & $56 \cdot 7$ & 1703 & 51.5 & 2192 & 62.5 \\
\hline \multirow[t]{2}{*}{ Central obesity§ } & 3490 & $50 \cdot 9$ & 1127 & $35 \cdot 5$ & 2363 & $68 \cdot 1$ \\
\hline & Mean & SE & Mean & SE & Mean & SE \\
\hline Acculturation index (range $0-5$ )\| & 2.4 & 0.1 & $2 \cdot 3$ & 0.1 & $2 \cdot 6$ & 0.1 \\
\hline
\end{tabular}

Missing data: age, $n$ 307; education, $n$ 319; PIR, $n$ 1005; married, $n$ 430; insurance status, $n$ 390; physical activity, $n$ 1249; smoking, $n 315$.

†Poverty-to-income ratio.

$\ddagger 2008$ Physical Activity Guidelines for Americans; moderate-intensity physical activity of $\geq 150$ min/week is needed.

$\S$ Central obesity: waist circumference $\geq 102 \mathrm{~cm}$ in men; $\geq 88 \mathrm{~cm}$ in women.

$\|$ Acculturation index is a score ranging from 0 to 5 ( 0 is the lowest acculturation and 5 is the highest acculturation). The index is derived from information of length of stay, nativity and language spoken at home.

Table 2 Healthy Eating Index-2010 (HEl-2010) total scores and component scores in Mexican-American men and women aged $\geq 20$ years $(n$ 6847), National Health and Nutrition Examination Survey (NHANES) 1999-2012

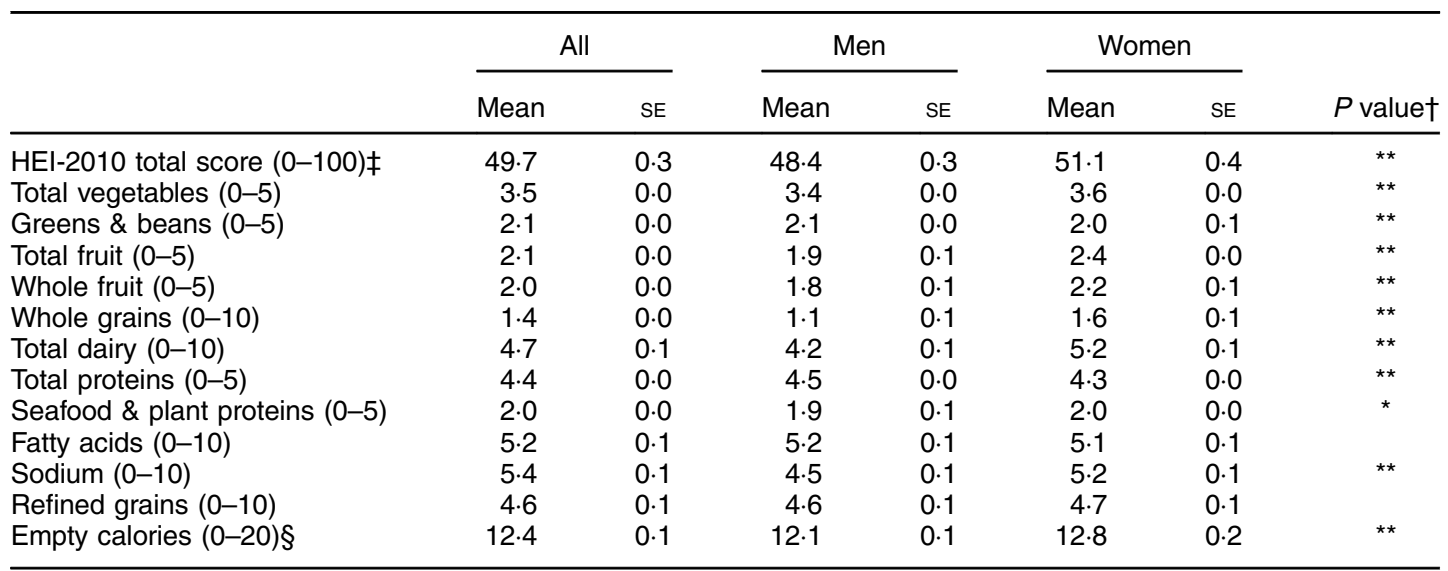

${ }^{\star} P<0.05,{ }^{* *} P<0.001$.

$\dagger P$ values are based on $t$ tests for differences in scores between men and women.

$\ddagger$ Score range for each $\mathrm{HEI}-2010$ category is given in parentheses; higher score means better quality.

$\S$ Empty calories are from solid fats, alcohol and added sugars. 
intake). However, a higher score of total proteins was associated with higher odds of central obesity (OR $=1 \cdot 08$; $95 \%$ CI 1.00, 1.16). When stratifying by gender, a higher whole fruit score was significantly associated with lower odds of central obesity in men (OR $=0.95$; $95 \%$ CI 0.90 , 0.99) but not in women. A higher sodium score was associated with lower odds of central obesity $(\mathrm{OR}=0.97$; $95 \%$ CI $0.94,0.99$ ) only in men.

\section{Discussion}

The present study found that Mexican-American women in general had better diet quality than Mexican-American men. This result is consistent with the finding in the general US adult population $^{(36)}$. The current study also suggested that a better HEI-2010 total score, indicating a better overall diet

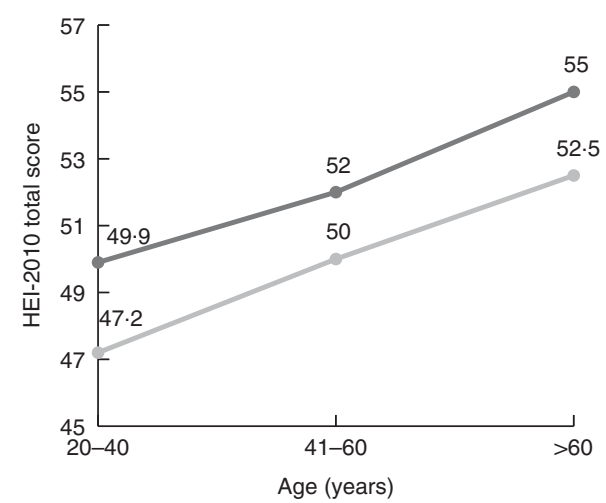

Fig. 1 Mean Healthy Eating Index-2010 (HEl-2010) total score, by gender (-०-, men; - - -, women) and age, among Mexican-American men and women aged $\geq 20$ years ( $n$ 6847), National Health and Nutrition Examination Survey (NHANES) 1999-2012 quality, was associated with a lower chance of central obesity among Mexican-American men. However, in women, the association was not significant. Some obesity studies have used gender-mixed samples or women-only samples ${ }^{(8,37)}$, and few studies have explored in detail the gender difference in diet quality and its association with central obesity among Mexican Americans. The lack of significance for HEI-2010 total score in Mexican-American women may be due to their higher HEI-2010 total scores than men. A higher HEI-2010 score may reflect women's greater emphasis on a healthy diet ${ }^{(23)}$, which may have resulted in a greater reporting bias in women than in men ${ }^{(16)}$. Another reason for this gender difference regarding diet quality and its effects on central obesity may be that immigrant men consume fast food more frequently than their female counterparts, possibly due to their preference of its ease and convenience, and their cooking and time limitations ${ }^{(38)}$. Beyond behaviour, basic biology may play a role. Biologically, men tend to store body fat in the abdominal region, whereas women tend to store fat in the lower extremities ${ }^{(39)}$. This biological difference in fat distribution between genders may also potentially explain the significant association between overall diet quality and central obesity among Mexican-American men.

In addition to overall diet quality, the present study also explored independent effects of fruits, proteins and sodium on central obesity. Even though few studies have examined the relationship between these dietary components and central obesity using the HEI measurement, some reported that increased intake of fruits has inverse relationships to anthropometric measures ${ }^{(3,15,40)}$. Fruits, which contain little cholesterol but are rich in vitamins, minerals and fibres, are essential for a healthy weight. Fruits also provide the body with phytochemicals including $\beta$-carotene, lutein and

Table 3 Logistic regression results of the associations between Healthy Eating Index-2010 (HEI-2010) total scores and component scores and central obesity in Mexican-American men and women aged $\geq 20$ years ( $n$ 6847), National Health and Nutrition Examination Survey (NHANES) 1999-2012

\begin{tabular}{|c|c|c|c|c|c|c|}
\hline & \multicolumn{6}{|c|}{ Central obesity†, } \\
\hline & \multicolumn{2}{|c|}{ All } & \multicolumn{2}{|c|}{ Men } & \multicolumn{2}{|c|}{ Women } \\
\hline & OR & $95 \% \mathrm{Cl}$ & OR & $95 \% \mathrm{Cl}$ & OR & $95 \% \mathrm{Cl}$ \\
\hline HEI-2010 total score & 0.99 & $0.99,1.00$ & $0.98^{*}$ & $0.98,1.00$ & 1.00 & $0.99,1.01$ \\
\hline Total vegetables & 0.99 & $0.95,1.05$ & 0.99 & $0.93,1.07$ & 1.01 & $0.95,1.07$ \\
\hline Greens \& beans & 0.99 & $0.97,1.03$ & 0.97 & $0.92,1.02$ & 1.03 & $0.98,1.07$ \\
\hline Total fruit & $0.96^{*}$ & $0.93,0.99$ & 0.95 & $0.90,1.00$ & 0.96 & $0.91,1.01$ \\
\hline Whole fruit & 0.97 & $0.94,1.00$ & $0.95^{\star}$ & $0.90,0.99$ & 0.99 & $0.95,1.03$ \\
\hline Whole grains & 0.99 & $0.96,1.03$ & 0.99 & $0.95,1.04$ & 0.99 & $0.95,1.04$ \\
\hline Total dairy & 0.99 & $0.97,1.02$ & 1.00 & $0.97,1.03$ & 0.98 & $0.95,1.01$ \\
\hline Total proteins & $1.08^{\star}$ & $1.00,1.16$ & 1.06 & $0.96,1.18$ & 1.09 & $1.00,1.19$ \\
\hline Seafood \& plant proteins & 1.00 & $0.97,1.04$ & 0.98 & $0.94,1.03$ & 1.02 & $0.97,1.07$ \\
\hline Fatty acids & 1.01 & $0.99,1.03$ & 0.99 & $0.97,1.02$ & 1.03 & $0.99,1.06$ \\
\hline Sodium§ & $0.98^{*}$ & $0.96,0.99$ & $0.97^{\star}$ & $0.94,0.99$ & 0.97 & $0.94,1.01$ \\
\hline Refined grains§ & 1.00 & $0.99,1.02$ & 1.00 & $0.98,1.03$ & 0.99 & $0.97,1.02$ \\
\hline Empty calories§ & 1.00 & $0.99,1.01$ & 0.99 & $0.97,1.01$ & 1.02 & $0.99,1.03$ \\
\hline
\end{tabular}

${ }^{*} P<0.05$.

†Odds of central obesity in Mexican Americans with a lower HEl-2010 score relative to odds of central obesity among individuals with higher HEl-2010 score. $\ddagger$ Adjusted for age, education, income, marriage status, insurance status, acculturation, smoking status and alcohol drinking status.

$\S$ Sodium, refined grains and empty calories are 'moderation' components, where a higher score indicates a lower level of intake. 
lycopene, which promote good health and reduce the risk for central obesity ${ }^{(41)}$. The beneficial effects of fruit intake may support the association between fruit score and central obesity found in the current study.

With respect to the finding concerning the relationship between sodium intake and the outcome, the current study showed that a higher sodium score, which reflects a lower level of intake, was associated with lower odds of central obesity in Mexican Americans. Moderate sodium intake is known to be effective in protecting cardiovascular health $^{(42-45)}$ and preventing and managing diabetes ${ }^{(46,47)}$. Researchers have studied a close link between sodium intake and weight gain. According to Karppanen and Mervaala $^{(45)}$, a high sodium intake obligatorily produces a progressive increase in thirst. The progressive increase in average intake of salt explains the observed concomitant increase in intake of sugar-sweetened or alcoholic beverages, which are sources of excessive energy intake ${ }^{(48-50)}$. Perhaps the high sodium intake together with intake of unhealthy beverages may help to explain the inverse relationship between sodium score (i.e. a higher score indicates a lower level of intake) and central obesity observed in Mexican Americans. Additionally, previous work has suggested that excessive sodium intake is often correlated with frequency of eating out and consumption of processed packaged foods and salty snacks ${ }^{(8,51)}$. Many Mexican Americans rely on ready-made processed foods and eating out because of the fast-paced life in the USA and the pressure to integrate into American society by eating American-style fast food ${ }^{(12,52,53)}$. According to the US Centers for Disease Control and Prevention, more than $75 \%$ of the sodium in the average American diet comes from salt added to processed foods ${ }^{(54)}$, which usually are energy-dense and a possible cause of obesity ${ }^{(55,56)}$. Salt is often used to preserve foods and modify flavour, and is included in additives that affect the texture or colour of foods ${ }^{(55)}$. When the consumption of processed foods and occasions of eating out increase, sodium intake is likely to increase and so too is the chance of gaining weight ${ }^{(54,55)}$. Perhaps the correlation between sodium intake and consumption of processed or restaurant foods can serve as another explanation for the relationship between sodium score and central obesity in Mexican Americans ${ }^{(51-56)}$.

The present study results also indicated that a higher score of total proteins, indicating a higher level of intake, was associated with increased odds of central obesity. Similar results regarding the association between protein intake and weight gain have been shown before ${ }^{(16,57,58)}$. One study assessed the association between diet quality measured by the HEI-2010 and body weight; it found that a high score of total proteins is associated with an increased risk for obesity ${ }^{(16)}$. The association was determined in a large US sample ${ }^{(57)}$, as well as in an all-women sample from the Framingham nutrition studies ${ }^{(58)}$. A potential explanation for the positive association between a higher level of protein intake and obesity outcomes is that there is a positive correlation between fat and total protein intake ${ }^{(16)}$. Meat or poultry may contribute a significant share of dietary protein for Mexican Americans ${ }^{(59)}$. The association between protein and central obesity is probably attributable to increased consumption of processed foods or red meat ${ }^{(60-62)}$; and it may be that these products are becoming a major source of proteins for Mexican Americans ${ }^{(59,62)}$. This places them at a higher risk for central obesity. Commercially prepared meats such as sandwich meats, bacon, salami or sausage are not only notoriously high in sodium but also high in fat ${ }^{(63)}$. Processed meats are made by grinding and combining fatty cuts of meat and they can be a potent but overlooked source of saturated fat and energy ${ }^{(64)}$. A recent study showed that Mexican Americans follow a meat-oriented dietary pattern, which includes primarily processed meats, rather than the traditional plant-based Mexican diet that relies on legumes as a major source of protein ${ }^{(59)}$. These dietary habits, along with the epidemiological evidence that increased processed meat intake increases the risk of chronic disease ${ }^{(65,66)}$, aid in understanding the association between the score of proteins and central obesity, and highlight the importance of promoting healthier protein alternatives such as plant-based protein foods.

\section{Study limitations}

The current study has several limitations. First of all, NHANES data are cross-sectional, which precluded examination of changes in diet quality and weight status in the cohort over time. Without a longitudinal design, associations can be assessed but evidence of a causal relationship between diet quality and central obesity cannot be established. Furthermore, the study was exclusively focused on Mexican Americans, so results may not be generalizable to other populations because of the variations within cultural practices and obesity risks across races/ethnicities. Additionally, it is possible that the study excluded some undocumented immigrants. This group of people may be less likely to participate in NHANES questionnaires or physical examinations due to fear of exposing their illegal status.

Measurements for some study variables may have incorporated errors. Although more exact methods exist for measuring visceral adipose tissue accumulation (e.g. MRI and computerized tomography), NHANES did not employ these exact methods. Previous studies have shown that waist circumference has a strong association with visceral adiposity ${ }^{(67)}$ and it is therefore the recommended measure to estimate the risk of CVD and type 2 diabetes for many populations ${ }^{(68-72)}$, including Mexican Americans.

Additionally, potential biases may exist in measuring diet. Under-reporting by participants is common in nutritional studies, especially among those who are overweight 
or obese ${ }^{(73)}$. Thus, the potential bias towards the null resulting from under-reporting is acknowledged. Extreme dietary intake values were excluded from the current study. Additionally, some scholars argue that the discrete distributions within HEI scoring patterns may reduce its power as a predictor ${ }^{(74)}$. Some are also concerned that arbitrary choices made in scoring HEI components may hamper its ability to predict risks for chronic diseases ${ }^{(58,75)}$. In fact, the insignificant finding on the relationship between empty calories and central obesity may demonstrate this limitation. The HEI-2010 considers alcohol above a threshold level indicative of moderate drinking as empty calories. This approach does not directly address other potential positive and negative biological effects of alcohol, nor does it account for specific questions related to frequency of consumption and amounts consumed on drinking occasions ${ }^{(11)}$. Perhaps the poor sensitivity of the HEI-2010 empty calories score in predicting central obesity can be partially explained by the limited information on alcohol measurement. Therefore, when using the HEI-2010 to examine relationships between diet quality and health outcomes, additional considerations regarding alcohol may be warranted ${ }^{(11)}$.

\section{Study strengths}

Despite the limitations, the study contributes to the literature by presenting national-scale evidence regarding the effect of diet quality on clinically validated central obesity among Mexican Americans. The current investigation utilizes a comprehensive measure of diet quality, which allows for an assessment of overall diet quality and major food group balances of Mexican Americans ${ }^{(47)}$. Most of the existing studies on diet have focused on specific nutrient components, such as fats and sugars, or on the consumption of individual food groups ${ }^{(8,9)}$. These nutritional outcomes have been critiqued as "being overly reductionist, failing to account for how foods are eaten in combination as part of meals or cuisines', according to Park et al. ${ }^{(76)}$. Total food intake is a complex construct, which cannot be described or evaluated based on nutrients measured in isolation from one another. The HEI-2010 is able to measure consumption levels of food groups and nutrients concurrently, which is a superior approach in estimating dietary intake ${ }^{(77)}$. It is also worthy to note that the HEI-2010's utilization of the density approach (i.e. as a percentage of energy consumed) allows for characterization of intake levels while controlling for total energy intake ${ }^{(78)}$, which is highly correlated with the quantity of foods consumed. This may further suggest the HEI-2010 is a better way to measure diet and to inform dietary modifications. Moreover, the study identified that specific aspects of diet, as indicated by HEI-2010 component scores, were related to central obesity. This may suggest particular areas for dietary interventions that are more targeted to the Mexican-American population. Additionally, a Mexican-American sample derived from a national survey data (i.e. NHANES) was used and genderstratified analyses were conducted. The analyses accounted for survey design complexity and yielded estimates for the nation as a whole. Findings may assist with designing gender-specific and culturally relevant solutions to tackle obesity-related disparities among Mexican Americans.

\section{Implications}

The current study findings assist in the understanding of diet quality and central obesity in Mexican Americans by demonstrating their diet quality and how it contributes to the central obesity among them. These findings may lend insights for community-level dietary interventions and national-level policies aimed at reducing the high rates of central obesity and related health problems among Mexican Americans. Nutrition professionals should consider promoting whole fruits that are culturally appropriate, as well as introducing Western produce to the community. Additionally, promoting home cooking as a strategy for reducing sodium intake may be beneficial for Mexican Americans, especially for Mexican-American men who may consume more fast food and have poorer cooking skills than their female counterparts ${ }^{(79)}$. It is essential that enhancing the understanding of food labels, of nutritional merits of different foods and of food preparation methods be incorporated into the dietary interventions. A regulatory approach that supports the food industry in the reformulation of foods is recommended ${ }^{(80)}$. If these efforts were implemented, they would provide greater flexibility for meeting the sodium intake guideline when individuals consume commercially prepared foods. It is also suggested that other protein-containing foods may better replace meat and poultry, especially processed meat products. The HEI-2010 includes a separate category for seafood and plant-based proteins, which indicates the awareness of the potential detrimental effects of animal-based protein. Scholars have suggested that rather than relying on absolute protein intake, a ratio of total protein to seafood and plant proteins may be a better indicator for a healthy diet ${ }^{(16)}$. As for practice, nutrition professionals should encourage the intake of healthier protein alternatives, such as legumes and seafood. Also, cheese made with lower-fat milk, including Hispanic-style cheeses available in lower-fat varieties such as Queso Oaxaca and Queso Fresco, can also be a healthy protein source to be promoted in the community.

\section{Conclusion}

The present study showed that, in general, MexicanAmerican women appeared to have better diet quality than their male counterparts. The study also revealed that a better diet quality was associated with a lower chance of central obesity among Mexican Americans, especially in Mexican-American men. In particular, component scores of fruits and sodium were inversely related to central 
obesity, but the score of total proteins was associated with higher odds of central obesity. To reduce the risks for central obesity in Mexican Americans, dietary interventions should focus on enhancing the diet quality, especially in the areas of fruit and healthy protein promotion as well as sodium reduction.

\section{Acknowledgements}

Financial support: This research received no specific grant from any funding agency in the public, commercial or not-for-profit sectors. Conflict of interest: None to disclose. Authorship: Y.Y. and T.-S.T. designed the research; Y.Y. analysed the data; Y.Y., R.S., L.C., S.B., S.P. and T.-S.T. wrote the manuscript and had responsibility for final content. All authors read and approved the final manuscript. Ethics of buman subject participation: The Research Ethics Review Board of the National Center for Health Statistics approved NHANES and informed consent was obtained from all participants.

\section{Supplementary material}

To view supplementary material for this article, please visit https://doi.org/10.1017/S1368980016003190

\section{References}

1. Morales LS, Flores YN, Leng M et al. (2014) Risk factors for cardiovascular disease among Mexican-American adults in the United States and Mexico: a comparative study. Salud Publica Mex 56, 197-205.

2. Ford ES, Maynard LM \& Li C (2014) Trends in mean waist circumference and abdominal obesity among US adults, 1999-2012. JAMA 312, 1151-1153.

3. Tande DL, Magel R \& Strand BN (2010) Healthy Eating Index and abdominal obesity. Public Health Nutr 13, 208-214.

4. Barquera S, Campos-Nonato I, Hernandez-Barrera L et al. (2010) Hypertension in Mexican adults: results from the National Health and Nutrition Survey 2006. Salud Publica Mex 52, Suppl. 1, S63-S71.

5. Folsom AR, Kaye SA, Sellers TA et al. (1993) Body fat distribution and 5-year risk of death in older women. JAMA 269, 483-487.

6. de Koning L, Merchant AT, Pogue J et al. (2007) Waist circumference and waist-to-hip ratio as predictors of cardiovascular events: meta-regression analysis of prospective studies. Eur Heart J 28, 850-856.

7. Sundquist J \& Winkleby MA (1999) Cardiovascular risk factors in Mexican American adults: a transcultural analysis of NHANES III, 1988-1994. Am J Public Health 89, 723-730.

8. Ayala GX, Baquero B \& Klinger S (2008) A systematic review of the relationship between acculturation and diet among Latinos in the United States: implications for future research. J Am Diet Assoc 108, 1330-1344.

9. Hu FB (2002) Dietary pattern analysis: a new direction in nutritional epidemiology. Curr Opin Lipidol 13, 3-9.

10. Fransen HP \& Ocke MC (2008) Indices of diet quality. Curr Opin Clin Nutr Metab Care 11, 559-565.
11. Guenther PM, Casavale KO, Reedy J et al. (2013) Update of the Healthy Eating Index: HEI-2010. J Acad Nutr Diet 113, 569-580.

12. Liu JH, Chu YH, Frongillo EA et al. (2012) Generation and acculturation status are associated with dietary intake and body weight in Mexican American adolescents. J Nutr 142, 298-305.

13. Jennings A, Welch A, van Sluijs EM et al. (2011) Diet quality is independently associated with weight status in children aged 9-10 years. J Nutr 141, 453-459.

14. Gao SK, Beresford SA, Frank LL et al. (2008) Modifications to the Healthy Eating Index and its ability to predict obesity: the Multi-Ethnic Study of Atherosclerosis. Am J Clin Nutr 88, 64-69.

15. Nicklas TA, O'Neil CE \& Fulgoni VL 3rd (2012) Diet quality is inversely related to cardiovascular risk factors in adults. J Nutr 142, 2112-2118.

16. Drenowatz C, Shook RP, Hand GA et al. (2014) The independent association between diet quality and body composition. Sci Rep 4, 4928.

17. Perez-Escamilla R (2011) Acculturation, nutrition, and health disparities in Latinos. Am J Clin Nutr 93, issue 5, 1163S-1167S.

18. Flegal KM, Ogden CL \& Carroll MD (2004) Prevalence and trends in overweight in Mexican-American adults and children. Nutr Rev 62, 2 Pt 2, S144-S148.

19. Khan LK, Sobal J \& Martorell R (1997) Acculturation, socioeconomic status, and obesity in Mexican Americans, Cuban Americans, and Puerto Ricans. Int J Obes Relat Metab Disord 21, 91-96.

20. Wang Y \& Beydoun MA (2007) The obesity epidemic in the United States - gender, age, socioeconomic, racial/ethnic, and geographic characteristics: a systematic review and meta-regression analysis. Epidemiol Rev 29, 6-28.

21. Guo X, Warden BA, Paeratakul S et al. (2004) Healthy Eating Index and obesity. Eur J Clin Nutr 58, 1580-1586.

22. Wansink B, Cheney MM \& Chan N (2003) Exploring comfort food preferences across age and gender. Physiol Behav 79, 739-747.

23. Wardle J, Haase AM, Steptoe A et al. (2004) Gender differences in food choice: the contribution of health beliefs and dieting. Ann Behav Med 27, 107-116.

24. Kant AK, Graubard BI \& Kumanyika SK (2007) Trends in black-white differentials in dietary intakes of US adults, 1971-2002. Am J Prev Med 32, 264-272.

25. Ribas-Barba L, Serra-Majem L, Salvador G et al. (2007) Trends in dietary habits and food consumption in Catalonia, Spain (1992-2003). Public Health Nutr 10, 1340-1353.

26. Kant AK \& Graubard BI (2005) A comparison of three dietary pattern indexes for predicting biomarkers of diet and disease. J Am Coll Nutr 24, 294-303.

27. Flegal KM, Carroll MD, Kit BK et al. (2012) Prevalence of obesity and trends in the distribution of body mass index among US adults, 1999-2010. JAMA 307, 491-497.

28. Bowie JV, Juon HS, Cho J et al. (2007) Factors associated with overweight and obesity among Mexican Americans and Central Americans: results from the 2001 California Health Interview Survey. Prev Chronic Dis 4, A10.

29. Wang J, Reininger BM, Cron S et al. (2012) Gender difference in obesity and preventive health behaviors in an US-Mexico border Hispanic cohort. Int J Exerc Sci 6, 2002.

30. National Center for Health Statistics (2016) About National Health and Nutrition Examination Survey. http://www.cdc. gov/nchs/nhanes/about_nhanes.htm (accessed September 2016).

31. US Department of Agriculture, Agricultural Research Service (2016) Food Pattern Equivalents Database. https://www.ars. usda.gov/northeast-area/beltsville-md/beltsville-humannutrition-research-center/food-surveys-research-group/docs/ fped-databases/ (accessed September 2016). 
32. Torpy JM, Lynm CL \& Glass RM (2006) The metabolic syndrome. JAMA 295, 850.

33. Heiss G, Synder M, Teng Y et al. (2014) Prevalence of metabolic syndrome among Hispanic/Latinos of diverse background: the Hispanic Community Health Study/Study of Latinos. Diabetes Care 37, 2391-2399.

34. Kandula NR, Diez-Roux AV, Chan C et al. (2008) Acculturation is associated with diabetes prevalence in the Multiethnic Study of Atherosclerosis. Diabetes Care 31, $1621-1628$.

35. US Department of Health and Human Services (2016) 2008 Physical activity guidelines for Americans. http://health. gov/paguidelines/guidelines/ (accessed September 2016).

36. US Department of Agriculture, Center for Nutrition Policy and Promotion (1995) The Healthy Eating Index. http:// www.cnpp.usda.gov/sites/default/files/healthy_eating_index/ HEI89-90report.pdf (accessed September 2016).

37. Perez-Escamilla R \& Putnik P (2007) The role of acculturation in nutrition, lifestyle, and incidence of type 2 diabetes among Latinos. J Nutr 137, 860-870.

38. Jasti S, Lee CH \& Doak C (2011) Gender, acculturation, food patterns, and overweight in Korean immigrants. Am J Health Behav 35, 734-745.

39. Blaak E (2011) Gender differences in fat metabolism. Curr Opin Clin Nutr Metab Care 4, 499-502.

40. Esposito K \& Giugliano D (2006) Beneficial effects of a Dietary Approaches to Stop Hypertension eating plan on features of the metabolic syndrome. Diabetes Care 29, 954

41. US National Institute of Health (2014) Senior Health, Eating Well as You Get Older. http://nihseniorhealth.gov/ eatingwellasyougetolder/choosenutrientdensefoods/01.html (accessed September 2016).

42. Whelton PK, He J, Appel LJ et al. (2002) Primary prevention of hypertension: clinical and public health advisory from the National High Blood Pressure Education Program. JAMA 288, 1882-1888.

43. Lanier JB, Bury DC \& Richardson SW (2016) Diet and physical activity for cardiovascular disease prevention. $A m$ Fam Physician 93, 919-924.

44. Smyth A, O'Donnell M, Mente A et al. (2015) Dietary sodium and cardiovascular disease. Curr Hypertens Rep 17, 559.

45. Karppanen H \& Mervaala E (2006) Sodium intake and hypertension. Prog Cardiovasc Dis 49, 59-75.

46. Leontos C (2003) Implementing the American Diabetes Association's nutrition recommendations. J Am Osteopath Assoc 103, 8 Suppl. 5, S17-S20.

47. Barclay A, Gilbertson H, Marsh K et al. (2010) Dietary management in diabetes. Aust Fam Physician 39, 579-583.

48. Grimes CA, Wright JD, Liu K et al. (2013) Dietary sodium intake is associated with total fluid and sugar-sweetened beverage consumption in US children and adolescents aged 2-18 y: NHANES 2005-2008. Am J Clin Nutr 98, 189-196.

49. Grimes CA, Riddell LJ, Campbell KJ et al. (2013) Dietary salt intake, sugar-sweetened beverage consumption, and obesity risk. Pediatrics 131, 14-21.

50. Choi KH, Park MS, Kim JA et al. (2015) Associations between excessive sodium intake and smoking and alcohol intake among Korean men: KNHANES V. Int J Environ Res Public Health 12, 15540-15549.

51. Mendoza JE, Schram GA, Arcand J et al. (2013) Assessment of consumers. level of engagement in following recommendations for lowering sodium intake. Appetite (Epublication ahead of print version)

52. Lindberg NM \& Stevens VJ (2011) Immigration and weight gain: Mexican-American women's perspectives. J Immigr Minor Health 13, 155-160.

53. Neuhouser ML, Thompson B, Coronado GD et al. (2004) Higher fat intake and lower fruit and vegetables intakes are associated with greater acculturation among Mexicans living in Washington State. J Am Diet Assoc 104, 51-57.
54. US Centers for Disease Control and Prevention (2016) Sodium and food sources. http://www.cdc.gov/salt/food. htm (accessed September 2016).

55. Ahuja JKC, Pehrsson PR, Haytowitz DB et al. (2015) Sodium monitoring in commercially processed and restaurant foods. Am J Clin Nutr 101, 622-631.

56. Monteiro CA, Moubarac JC, Cannon G et al. (2013) Ultra-processed products are becoming dominant in the global food system. Obes Rev 14, Suppl. 2, 21-28.

57. Shay CM, Van Horn L, Stamler J et al. (2012) Food and nutrient intakes and their associations with lower BMI in middle-aged US adults: the International Study of Macro-/ Micronutrients and Blood Pressure (INTERMAP). Am J Clin Nutr 96, 483-491.

58. Wolongevicz DM, Zhu L, Pencina MJ et al. (2010) Diet quality and obesity in women: the Framingham Nutrition Studies. Br J Nutr 103, 1223-1229.

59. Carrera PM, Gao X \& Tucker KL (2007) A study of dietary patterns in the Mexican-American population and their association with obesity. J Am Diet Assoc 107, 1735-1742.

60. Cristofoletti MF, Gimeno SG, Ferreira SR et al. (2013) Association of processed meat intake and obesity in a population-based study of Japanese-Brazilians. Arq Bras Endocrinol Metabol 57, 464-472.

61. Halkjaer J, Tjønneland A, Overvad K et al. (2009) Dietary predictors of 5-year changes in waist circumference. J Am Diet Assoc 109, 1356-1366.

62. Wang Y, Beydoun MA, Caballero B et al. (2010) Trends and correlates in meat consumption patterns in the US adult population. Public Health Nutr 13, 1333-1345.

63. Bovalino S, Charleson G \& Szoeke C (2015) The impact of red and processed meat consumption on cardiovascular disease risk in women. Nutrition 32, 349-354.

64. Kaluza J, Akesson A \& Wolk A (2014) Processed and unprocessed red meat consumption and risk of heart failure: prospective study of men. Circ Heart Fail 7, 552-557.

65. Wu K, Spiegelman D, Hou T et al. (2016) Associations between unprocessed red and processed meat, poultry, seafood and egg intake and the risk of prostate cancer: a pooled analysis of 15 prospective cohort studies. Int J Cancer 138, 2368-2382.

66. Boada LD, Henríquez-Hernández LA \& Luzardo OP (2016) The impact of red and processed meat consumption on cancer and other health outcomes: epidemiological evidences. Food Chem Toxicol 92, 236-244.

67. Sundquist J \& Winkleby M (2000) Country of birth, acculturation status and abdominal obesity in a national sample of Mexican-American women and men. Int J Epidemiol 29, 470-477.

68. Knowles KM, Paiva LL, Sanchez SE et al. (2011) Waist circumference, body mass index, and other measures of adiposity in predicting cardiovascular disease risk factors among Peruvian Adults. Int J Hypertens 2011, 931402.

69. Vazquez G, Duval S, Jacobs DR Jr et al. (2007) Comparison of body mass index, waist circumference, and waist/ hip ratio in predicting incident diabetes: a meta-analysis. Epidemiol Rev 29, 115-128.

70. Zhang C, Rexrode KM, van Dam RM et al. (2008) Abdominal obesity and the risk of all-cause, cardiovascular, and cancer mortality: sixteen years of follow-up in US women. Circulation 117, 1658-1667.

71. Mamtani M, Kulkarni H, Dyer TD, Almasy L et al. (2014) Waist circumference is genetically correlated with incident type 2 diabetes in Mexican-American families. Diabet Med 31, 31-35.

72. Wei M, Gaskill SP, Haffner SM et al. (1997) Waist circumference as the best predictor of noninsulin dependent diabetes mellitus (NIDDM) compared to body mass index, waist/hip ratio and other anthropometric measurements in Mexican Americans - a 7-year prospective study. Obes Res 5, 16-23. 
73. Fisher JO, Johnson RK, Lindquist C et al. (2010) Influence of body composition on the accuracy of reported energy intake in children. Obes Res 8, 597-603.

74. Wirt A \& Collins CE (2009) Diet quality - what is it and does it matter? Public Health Nutr 12, 2473-2492.

75. Waijers PM, Feskens EJ \& Ocke MC (2007) A critical review of predefined quality scores. Br J Nutr 97, 219-231.

76. Park Y, Neckerman K, Quinn J et al. (2011) Neighbourhood immigrant acculturation and diet among Hispanic female residents of New York City. Public Health Nutr 14, 1593-1600.

77. Guenther PM, Kirkpatrick SI, Reedy J et al. (2014) The Healthy Eating Index-2010 Is a valid and reliable measure of diet quality according to the 2010 Dietary Guidelines for Americans. J Nutr 144, 399-407.

78. Guenther PM, Reedy J, Krebs-Smith SM et al. (2007) Development and evaluation of the Healthy Eating Index2005: Technical Report. http://www.cnpp.usda.gov/ HealthyEatingIndex.htm (accessed September 2016).

79. Larson NI, Perry CL, Story M et al. (2006) Food preparation by young adults is associated with better diet quality. $J \mathrm{Am}$ Diet Assoc 106, 2001-2007.

80. US Institute of Medicine, Panel on Dietary Reference Intakes for Electrolytes and Water (2005) Dietary Reference Intakes for Water, Potassium, Sodium, Chloride, and Sulfate. Washington, DC: National Academies Press. 